\title{
A PRÁTICA DO TRABALHO INFANTIL ENTRE OS BENEFICIÁRIOS DO PROGRAMA BOLSA-ESCOLA BELO HORIZONTE: UM ESTUDO SOBRE OS DETERMINANTES SOCIODEMOGRÁFICOS
}

\author{
Michelle dos Santos Diniz \\ Ada Ávila AssunçÃo* \\ WALESKA TEIXEIRA CAIAFFA** \\ MERY NATALI SILVA ABREu ${ }^{* * * * *}$
}

\begin{abstract}
RESUMO: O trabalho infantil atinge mais de cinco milhões de crianças e adolescentes no Brasil e é atribuído principalmente à pobreza. Este artigo tem por objetivo estudar as características das famílias com e sem registro de trabalho infantil inscritas no Programa Bolsa-Escola de Belo Horizonte e comparar os dois grupos para se detectar fatores possivelmente associados ao trabalho infantil. Foi realizado estudo transversal com 9.252 famílias participantes do programa, de 2003 a 2006, com enfoque nas características do domicílio, da mãe e da família. Entre as 9.252 famílias estudadas, 1.293 $(13,9 \%)$ apresentaram registro de trabalho infantil. Observou-se relação positiva entre a ocorrência de trabalho infantil e o maior número de pessoas na casa, ausência do cônjuge no domicílio, baixa escolaridade da mãe e inserção trabalhista da mãe. Apesar da consolidação do programa, o trabalho infantil continua presente entre os bolsistas. Além da pobreza, outros fatores podem contribuir para o trabalho infantil.
\end{abstract}

Palavras-chave: Trabalho infantil. Programa Bolsa-Escola. Programas de transferência de renda.

Mestre em Saúde Pública pela Universidade Federal de Minas Gerais (UFMG).

E-mail: michellesdmi@yahoo.com.br

** Doutora em Ergonomia e professora do Programa de Pós-Graduação em Saúde Pública, da Faculdade de Medicina da UFMG. E-mail: adavila@medicina.ufmg.br

*** Doutora em Parasitologia e professora titular do Departamento de Medicina Preventiva e Social, da Faculdade de Medicina da UFMG. E-mail: wcaiaffa@medicina.ufmg.br

**** Doutoranda do Programa de Pós-Graduação em Saúde Pública/Epidemiologia, da Faculdade de Medicina da UFMG. E-mail: merynatali@yahoo.com.br 


\title{
THE PRACTICE OF CHILD LABOR BETWEEN BENEFICIARY OF “BOLSA-ESCOLA PROGRAM" IN BELO HORIZONTE: A STUDY OF THE SOCIO-DEMOGRAPHIC DETERMINANTS
}

\begin{abstract}
Child labor affects more than five million of children and adolescents in Brazil. It is mainly attributed to poverty. This article aims to study the characteristics of families with and without records of child labor registered in the Bolsa-Escola Program in Belo Horizonte city, and to compare the two groups in order to identify factors possibly associated with child labor. It is a cross-sectional study of 9,252 families that took part in the Program from 2003 to 2006. It were analyzed the characteristics of the home, the mother and family. Among the 9,252 families studied, 1,293 (13.9\%) had a record of child labo $\mathrm{r}$. There was positive relationship between the occurrence of child labor and the greatest number of people in the house, the absence of the husband at home, low level of maternal education, and labor market insertion of the mother. Despite the consolidation of the Program, child labor still exists in these families. In addition to poverty, other factors may contribute to child labor.
\end{abstract}

Key words: Child labor. Bolsa-Escola Program. Cash transfer program.

\section{LA PRATIQUE DU TRAVAIL INFANTILE PARMI LES BÉNÉFICIAIRES DU programme Bourse-Ecole de Belo Horizonte: une Étude sur LES DÉTERMINANTS SOCIO-DÉMOGRAPHIQUES}

RÉSUMÉ: Le travail infantile concerne plus de cinq millions d'enfants et adolescents au Brésil et est attribué principalement à la pauvreté. Cet article a pour objectif d'étudier les caractéristiques des familles avec et sans indice de travail infantile inscrites au programme Bourse-Ecole de Belo Horizonte et de comparer les deux groupes pour détecter des facteurs pouvant être associés au travail infantile. Une étude transversale a été réalisée avec 9252 familles participantes du Programme de 2003 à 2006 ayant pour cible les caractéristiques du domicile, de la mère et de la famille. Parmi les 9252 familles étudiées, $1293(13,9 \%)$ ont démontré des indices de travail infantile. On a observé une relation positive entre le fait du travail infantile et le plus grand nombre de personnes à la maison, l'absence de conjoint au domicile, la faible scolarité de la mère, et l'insertion professionnelle de la mère. Malgré la consolidation du Programme, le travail infantile continue présent parmi les boursiers. Outre la pauvreté, d'autres facteurs peuvent contribuer au travail infantile.

Mots-clés: Travail infantile. Programme Bourse-Ecole. Programme de transfert de revenus.

\section{Introdução}

7 rabalho infantil é aquele que expõe a criança e o adolescente à disciplina do trabalho, prejudicando a formação e a saúde de seus organismos frágeis (Brasil, 2000). De acordo com o Estatuto da Criança e do Adolescente, considera-se criança a pessoa de até 12 anos de idade e adolescente aquela entre 12 e 18 anos de idade (Brasil, 1990). 
O trabalho infantil foi um dos primeiros e mais importantes problemas tratados pela comunidade mundial. Desde a primeira Conferência da Organização Internacional do Trabalho (OIT) em 1919 foram adotadas normas para se tentar eliminar o trabalho infantil (OIT, 2006). Estimativas da OIT sugerem que, em 2004, havia 218 milhões de crianças e adolescentes entre 5 e 17 anos em situação de trabalho infantil no mundo. No Brasil, a Pesquisa Nacional por Amostra de Domicílios (PNAD), em 2006, identificou 5,1 milhões de crianças e adolescentes trabalhando, cerca de 5,7\% do total da população brasileira ocupada e $11,5 \%$ da população nesta faixa etária. Entretanto, observa-se uma tendência universal de queda na ocorrência do trabalho infantil (Cardoso \& Souza, 2003; Campos \& Alverga, 2001): entre 2000 e 2004, o número de crianças trabalhando no mundo reduziu de 246 milhões para 218 milhões. No Brasil, a cifra de 5,4 milhões em 2001 caiu para 5,1 milhões em 2006 (IBGE, 2007).

De acordo com o mapa de indicativos do trabalho da criança e do adolescente (MTE \& SIT, 2005), a redução do número de crianças e adolescentes trabalhadores de 1995 a 2002 deu-se principalmente nos estados de Maranhão, Distrito Federal, Alagoas, Sergipe e Rio Grande do Norte. Entretanto, registra-se aumento da ocorrência do trabalho infantil em outros estados brasileiros. Entre eles, apenas a Paraíba e o Piauí estão localizados nas regiões mais pobres. Nota-se uma tendência de "urbanização" da ocorrência do trabalho infantil, o qual predominava, anteriormente, no meio rural e hoje é mais frequente no meio urbano. A migração da população para as cidades pode explicar essa tendência. O mapa evidencia mais de $60 \%$ de crianças e adolescentes trabalhadores de 10-15 anos de idade sem nenhum rendimento e o predomínio, dois terços, do sexo masculino no grupo. Em torno de $90 \%$ das crianças que trabalham também frequentam a escola.

A redução do trabalho infantil pode ser atribuída, pelo menos em parte, ao trabalho constante de instituições governamentais e não governamentais (Marques, Neves \& Carvalho Neto, 2002). Diversas ações governamentais desenvolvidas no setor educacional têm sido consideradas estratégias relevantes não só para manter a criança na escola, mas também para provocar uma redução gradual do trabalho infantil no Brasil. Sabe-se que crianças e adolescentes que trabalham apresentam frequência escolar menor em relação àqueles que não trabalham (IBGE, 2007) e também maior índice de reprovação escolar com atraso e evasão prematura da escola (Facchini et al., 2003).

Entre os países da América Latina, o Brasil é pioneiro na implantação de programas de transferência de renda aliados aos objetivos de saúde ou de educação. O Programa Bolsa-Escola é o primeiro a desviar o foco da assistência social para o desenvolvimento social (Pero \& Szerman, 2005; Carvalho, 2004; Aguiar \& Araújo, 2002). Estudos sugerem que programas de transferência de renda condicionados são efetivos no aumento do uso de serviços preventivos pela população e também na melhoria dos indicadores de saúde (Lagarde et al., 2007). 
Os fatores que contribuem para a inserção precoce no mercado de trabalho constituem objeto de grande complexidade (Ávila, 2007; Franklin et al., 2001). Apesar de a pobreza assumir destaque entre as causas do trabalho infantil (Cardoso \& Souza, 2003; Ferreira, 2001; Oliveira \& Robazzi, 2001), há evidências de outros fatores a ela associados.

Destaca-se a família nesta investigação sobre o trabalho infantil. Na atualidade, tendências e comportamentos são determinados no âmbito familiar, o qual se configura em instância principal para o indivíduo que se encontra em situações difíceis (Cepal, 2006). A decisão sobre a inserção da criança e do adolescente no mercado de trabalho extrapola as motivações pessoais e perpassa o contexto familiar, incluindo as características socioculturais e a estrutura da família.

Este trabalho visa estudar as características das famílias com e sem registro de trabalho infantil inscritas no Programa Bolsa-Escola de Belo Horizonte (BEM$\mathrm{BH}$ ) e comparar estes dois grupos com o objetivo de se detectar fatores possivelmente associados à prática do trabalho infantil.

\section{Material e métodos}

Estudo transversal que identifica e compara características das famílias participantes do BEM-BH com e sem registro de trabalho infantil (TI). Diante da inexistência de uma fonte única para os dados de interesse (registro de prática de TI e características das famílias que compõem o universo da pesquisa), adotou-se a estratégia de trabalhar duas fontes distintas de dados existentes no BEM-BH. A primeira, como se verá adiante, é constituída por múltiplos impressos e não está processada. A segunda diz respeito às características sociodemográficas das famílias sem nenhuma menção ao trabalho infantil e se encontra inteiramente informatizada.

\section{População e período do estudo}

A população estudada corresponde às famílias beneficiárias do BEM-BH no período de junho de 2003 a julho de 2004 e que continuavam no programa em outubro de 2006.

O número de famílias inscritas no programa é flutuante. A cada mês famílias são desligadas e outras são cadastradas. Neste estudo, foram incluídas somente as famílias que estavam presentes nos dois momentos da pesquisa (2003/2004 e 2006) em razão da disponibilidade de obtenção dos dados necessários à realização da investigação (Figura 1). 


\section{Figura 1}

Diagrama explicativo da seleção da população do estudo

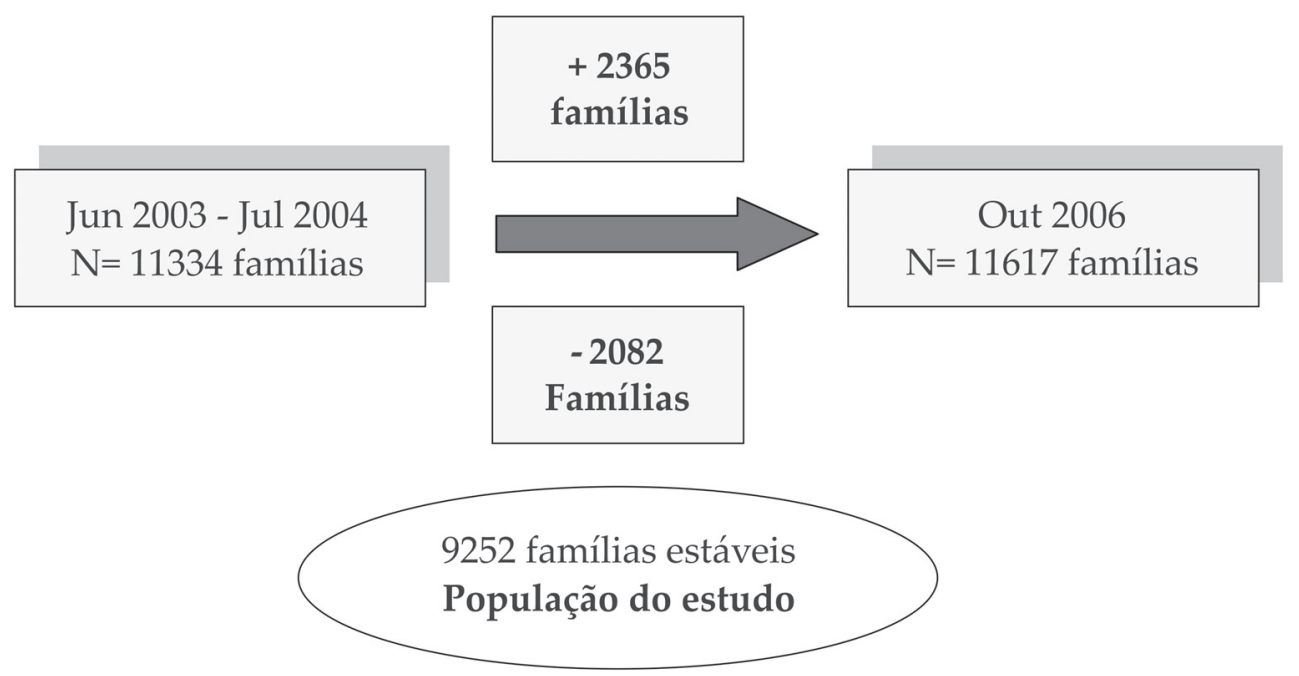

\section{Fonte de dados}

Os dados foram coletados de duas fontes:

Fonte 1: Formulários das famílias presentes no programa no período de junho de 2003 a julho de 2004.

Para cada família existe um formulário, o qual consta de vários impressos destinados, cada um, a fins específicos. Para efeitos de clareza, pode-se classificar o conjunto de impressos que compõe cada formulário em três campos: 1) inscrição da família no programa; 2) visitas domiciliares; 3) diversos. O formulário de inscrição foi preenchido por estagiários do BEM-BH no momento do cadastramento da família no programa com o intuito de colher dados sobre a requerente e seu universo familiar. Constam informações detalhadas sobre situação financeira, moradia, assistência social, saúde, núcleo familiar. O formulário de visita domiciliar é preenchido no intuito de comprovar os dados declarados na inscrição e de avaliar a realidade familiar. Nesse formulário estão registrados os dados cadastrais, as informações sobre condições de moradia, condições de higiene e organização do espaço, crianças ou adolescentes fora da escola, renda familiar, condições de saúde e observações gerais registradas durante a visita domiciliar. Outros impressos dizem respeito aos formulários de avaliação de permanência no BEM-BH, preenchidos anualmente por ocasião da convocação da mãe visando avaliar melhorias nas condições de moradia, alimentação e saúde. Encontram-se anexos avulsos de 
visitas domiciliares e convocações extraordinárias, por exemplo casos de ausência à escola, risco social ou denúncias de gasto indevido do benefício, entre outros motivos. Esses avulsos são preenchidos por estagiários e/ou funcionários do programa nos quais constam o resumo dos relatos da mãe. Não há campo específico para o registro de ocorrência de TI nem busca sistemática dessa informação. No entanto, encontra-se a informação sobre TI em qualquer um dos formulários referidos. No âmbito desta pesquisa, procedeu-se a uma leitura sistemática de todos os impressos na busca do registro de TI.

Fonte 2: Dados secundários disponíveis no sistema informatizado do BEM$\mathrm{BH}$ e construído para controle. Esses dados correspondem às características gerais das famílias relatadas no ato de inscrição de cada um dos beneficiários do programa (Anexo 1) no mês de outubro de 2006. As informações são de natureza estrutural, como afirmado acima, por isso são dificilmente alteradas em curto espaço de tempo, por exemplo as condições do domicílio.

\section{Procedimento de coleta de dados}

Diante da ausência de informação processada sobre a ocorrência de TI, optouse por buscar as informações registradas manual e aleatoriamente no formulário de cada família, para, em seguida, buscar as características das famílias na fonte 2 . No período de junho de 2003 a julho de 2004 procedeu-se à leitura dos campos que compõem o formulário de cada família beneficiária do programa (fonte 1) em busca de relato atual ou prévio de práticas de trabalho infantil presente nas famílias. Destaca-se que o registro de trabalho infantil era feito de forma não sistemática a partir do relato espontâneo dos beneficiários e da anotação dos técnicos da PBH nos formulários. Não havia, em nenhum formulário, um local específico destinado ao questionamento formal sobre o trabalho infantil. Os dados obtidos foram processados e permitiram a construção de um banco de dados (banco de dados 1), o qual reúne os registros de inscrição das famílias (código domiciliar) e a informação da presença ou não de trabalho infantil.

Os dados correspondentes às características sociodemográficas das famílias no momento em que elas ingressaram no programa foram extraídos do sistema de informação do BEM-BH (fonte 2) em outubro de 2006. Esses dados foram utilizados para a elaboração do banco de dados 2, o qual inclui todas as famílias inscritas no período e suas características obtidas das fichas de inscrição.

Foram selecionados os seguintes campos do banco de dados 2:

- Características do domicílio: campos 213 (situação); 214 (tipo); 215 (número de cômodos); 216 (tipo de construção); 217 (tipo de abastecimento 
de água); 218 (tratamento de água); 219 (tipo de iluminação); 220 (escoamento sanitário); 221 (destino do lixo no domicílio).

- Características da mãe/responsável legal pela família: 212 (estado civil); 213 (se o esposo ou companheiro reside no domicílio); 238 (grau de instrução); 242 (situação no mercado de trabalho); 270 (participa de algum programa do governo federal ou recebe algum benefício social).

- Características da família: renda familiar (obtida pela soma de todos os rendimentos dos membros familiares feita pela PBH); 222 (quantidade de pessoas); 225 (quantidade de deficientes).

\section{Variáveis do estudo}

1. Variável dependente

A variável dependente é o registro de trabalho infantil nas fichas das famílias beneficiárias. Trabalho infantil foi considerado qualquer atividade laborativa regular, remunerada ou não, domiciliar ou não (Facchini et al., 2003), realizada por crianças e adolescentes até 18 anos de idade incompletos.

2. Variáveis independentes

As variáveis independentes foram distribuídas em três categorias, sendo elas: características do domicílio, características da mãe e características da família (Tabela 1).

\section{Processamento e análise dos dados}

Os dados da fonte 1 foram coletados diretamente dos formulários e, sem seguida, foram informatizados. Elaborou-se uma planilha no Excel contendo o número de registro da família e a variável trabalho infantil ( $\mathrm{n}=11.334$ famílias). As informações da fonte de dados 2 estavam processadas em planilha Excel ( $\mathrm{n}=11.617$ famílias).

Posteriormente, os dois bancos de dados foram unificados e transferidos para o Programa SPSS11.5, o qual foi utilizado na análise dos dados (Figura 2). Esse banco de dados final incluiu o registro de todas as famílias presentes simultaneamente nos dois bancos $(n=9.252)$ e as respectivas informações sobre a presença de trabalho infantil e as características sociodemográficas (variáveis independentes) de cada família. 


\section{Tabela 1}

Variáveis independentes utilizadas no estudo e suas descrições

\begin{tabular}{|c|c|c|}
\hline & Variável & Descrição \\
\hline \multirow{9}{*}{$\begin{array}{l}\text { Características } \\
\text { do domicílio }\end{array}$} & Tipo de construção & $\begin{array}{l}\text { Tijolo/alvenaria ou outros } \\
\text { (adobe, madeira, material aproveitado, taipa) }\end{array}$ \\
\hline & $\begin{array}{l}\text { Tipo de abastecimento } \\
\text { de água }\end{array}$ & $\begin{array}{l}\text { Rede pública ou outros } \\
\text { (poço/nascente, carro-pipa) }\end{array}$ \\
\hline & Tratamento de água & $\begin{array}{l}\text { Com tratamento (filtração, fervura ou cloração) } \\
\text { ou sem tratamento }\end{array}$ \\
\hline & Tipo de iluminação & $\begin{array}{l}\text { Relógio (próprio ou comunitário) ou outros } \\
\text { (sem relógio, lampião, vela) }\end{array}$ \\
\hline & Escoamento sanitário & $\begin{array}{l}\text { Rede pública ou outros (fossa rudimentar, } \\
\text { séptica, vala, céu aberto) }\end{array}$ \\
\hline & Destino do lixo & $\begin{array}{l}\text { Coletado ou outros } \\
\text { (queimado, enterrado, céu aberto) }\end{array}$ \\
\hline & Tipo de domicílio & Apartamento/casa ou outros (cômodos) \\
\hline & Situação do domicílio & $\begin{array}{l}\text { Próprio ou alugado/financiado ou outros } \\
\text { (arrendado, cedido, invasão) }\end{array}$ \\
\hline & Número de cômodos & Quatro ou menos ou cinco ou mais \\
\hline \multirow{5}{*}{$\begin{array}{l}\text { Características } \\
\text { da mãe }\end{array}$} & Cônjuge no domicílio & Presença ou ausência do cônjuge no domicílio \\
\hline & $\begin{array}{l}\text { Participação em outros } \\
\text { programas do governo }\end{array}$ & $\begin{array}{l}\text { Participação ou não em outros programas do } \\
\text { governo }\end{array}$ \\
\hline & $\begin{array}{l}\text { Grau de instrução da } \\
\text { mãe }\end{array}$ & $\begin{array}{l}\text { 0-3 anos; } 4-7 \text { anos; 8-10 anos; mais de } 10 \text { anos de } \\
\text { estudo }\end{array}$ \\
\hline & Estado civil & $\begin{array}{l}\text { Casada ou outros (solteira, divorciada, } \\
\text { separada, viúva) }\end{array}$ \\
\hline & $\begin{array}{l}\text { Situação no mercado } \\
\text { de trabalho }\end{array}$ & $\begin{array}{l}\text { Com inserção trabalhista (empregador, } \\
\text { assalariada com/sem carteira de trabalho, } \\
\text { autônoma com/sem previdência social, } \\
\text { aposentada/pensionista, trabalhador/ } \\
\text { empregador rural) ou sem inserção trabalhista }\end{array}$ \\
\hline
\end{tabular}




\begin{tabular}{|c|l|l|}
\hline \multirow{4}{*}{$\begin{array}{c}\text { Características } \\
\text { da família }\end{array}$} & $\begin{array}{l}\text { Número de pessoas } \\
\text { na casa }\end{array}$ & $\begin{array}{l}\text { Até quatro pessoas na casa ou cinco ou mais } \\
\text { pessoas na casa }\end{array}$ \\
\cline { 2 - 3 } & $\begin{array}{l}\text { Presença de pessoas } \\
\text { com deficiência }\end{array}$ & $\begin{array}{l}\text { Presença ou ausência de pessoas com } \\
\text { deficiência }\end{array}$ \\
\cline { 2 - 3 } & Renda per capita & $\begin{array}{l}\mathrm{R} \$ 0-25,71 ; \mathrm{R} \$ 25,72-45,00 ; \mathrm{R} \$ 45,01-82,97 ; \\
\mathrm{R} \$ 82,98\end{array}$ \\
\hline
\end{tabular}

\section{Figura 2}

Diagrama explicativo da elaboração dos bancos de dados

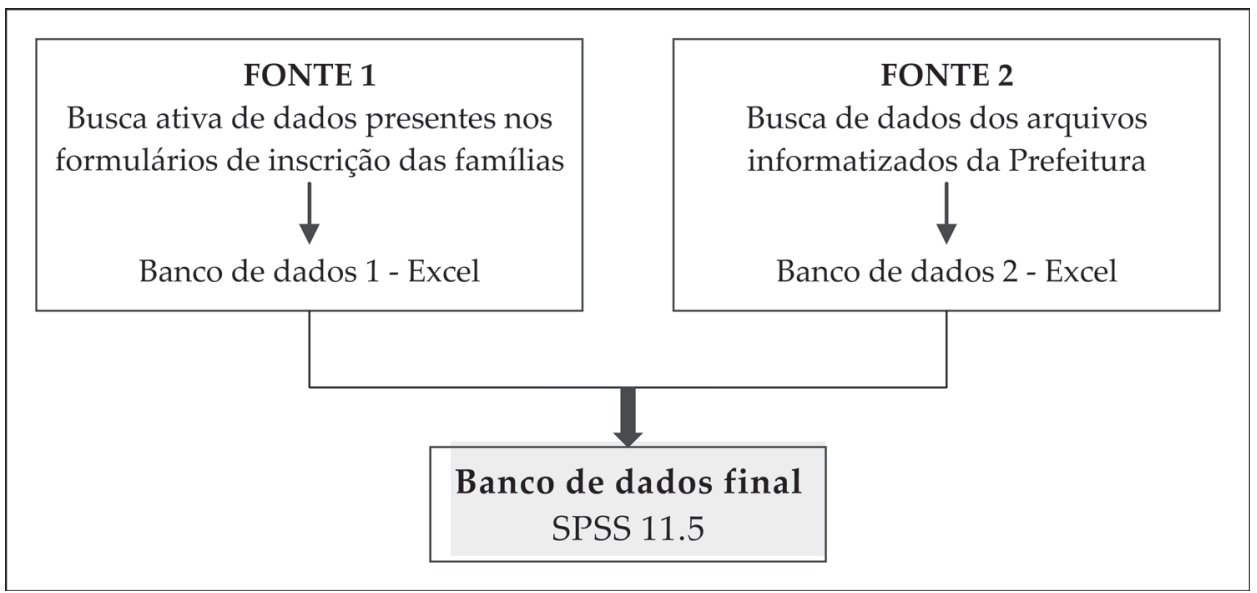

A variável renda familiar per capita foi elaborada dividindo-se o valor da renda familiar pelo número de pessoas na casa. Os dados disponíveis permitiram dimensionar a contribuição do trabalho infantil para a renda familiar. Procedeu-se à categorização das demais variáveis de interesse para a análise, utilizando-se a medida de tendência central mediana no caso das variáveis número de pessoas na casa e número de cômodos e a distribuição de percentis (25/50/75) para a variável renda familiar per capita.

\section{a) Análise descritiva}

Realizou-se a distribuição de frequências das variáveis, permitindo estabelecer as características da população estudada.

Foi utilizado o Índice de Kappa com Intervalo de Confiança (IC) ao nível de 95\% para estimar a concordância entre as variáveis número de cômodos e número 
de pessoas no domicílio após sua categorização. Avaliou-se também a correlação entre as variáveis estado civil e presença do cônjuge na casa.

Com relação à variável renda per capita, procurou-se identificar o número de famílias com renda per capita acima do valor permitido para inclusão no programa $(\mathrm{R} \$ 84,00)$.

b) Análise univariada

A análise univariada foi realizada para determinar a existência de associação entre as variáveis independentes já descritas e a presença de trabalho infantil nas famílias. Realizou-se uma análise estratificada das variáveis renda familiar per capita e escolaridade da mãe.

Para a análise utilizou-se o teste do Qui-quadrado de Pearson. As Razões de Chances (Odds Ratios) foram calculadas para determinar as forças das associações entre as variáveis. A opção por esta medida de associação se justifica por duas razões: a prevalência de TI é menor que $20 \%$, sendo assim, não há diferença substancial entre os diferentes estimadores de risco (Schiaffino et al., 2002); a razão das chances garante uma análise mais clara (Pearce, 2004). Calculou-se o intervalo de confiança e o valor $\mathrm{p}$ com um nível de significância de $5 \%(\mathrm{p}=0,05)$.

\section{c) Análise multivariada}

A regressão logística múltipla foi utilizada para determinar o efeito independente de cada variável. Foram selecionadas para inclusão nos modelos logísticos as variáveis que apresentaram, na análise univariada, associação com o trabalho infantil no nível inferior a $20 \%(\mathrm{p}<0,20)$ e um valor de informações incompletas menor que $20 \%$. A técnica utilizada na seleção do modelo foi a de eliminação backward. Procurou-se identificar a presença de colinearidade. A adequação do modelo foi avaliada pelo teste de Hosmer e Lemeshow. Para permanência das variáveis no modelo final, considerou-se um nível de significância de 5\% (Pagano \& Gauvreau, 2006).

Após a realização da análise multivariada foi calculado o poder de detecção da amostra. Foram estimadas as probabilidades de ocorrência de trabalho infantil, baseadas no modelo final de regressão.

Os cuidados éticos foram tomados. A pesquisa foi submetida ao Comitê de Ética em Pesquisa da UFMG, sendo aprovado em 1/7/2004 (ETIC 073/04).

\section{Resultados}

Entre as famílias incluídas na pesquisa ( $\mathrm{n}=9.252), 1.293$ (13,9\%) apresentaram pelo menos um registro de TI. Quanto às características do domicílio, observou-se 
um grande porcentual de informações incompletas $(66,7 \%)$, o que compromete a validade interna dos resultados. A incompletude no grupo de famílias com registro de TI foi de $84,6 \%$ e no grupo sem trabalho infantil foi de 63,7\%; não foram, portanto, homogêneas. Excetuando-se as variáveis tratamento de água e número de cômodos, as demais variáveis não apresentaram diferença estatisticamente significativa entre os grupos com e sem registro de trabalho infantil. Com relação ao tratamento de água, observou-se que famílias com algum tipo de tratamento de água apresentaram maior porcentagem de trabalho infantil $(6,9 \%)$ em relação às famílias sem tratamento de água $(4,5 \%)$. O trabalho infantil também foi encontrado com maior frequência nas famílias com maior número de cômodos no domicílio (cinco ou mais) em relação àquelas que habitam em locais com quatro ou menos cômodos (Tabela 2).

\section{Tabela 2}

Características do domicílio das famílias inscritas no BEM-BH (2003-2006) e a presença de trabalho infantil*

\begin{tabular}{|c|c|c|c|c|c|}
\hline \multirow{2}{*}{ Variável } & \multicolumn{2}{|c|}{ Trabalho infantil } & \multirow{2}{*}{ Valor $p$} & \multirow{2}{*}{ Odds Ratio } & \multirow{2}{*}{ IC $(95 \%)$} \\
\hline & Não (\%) & $\operatorname{Sim}(\%)$ & & & \\
\hline \multicolumn{6}{|l|}{$N^{\circ}$ de cômodos } \\
\hline 4 ou menos & $1827(94,4)$ & $108(5,6)$ & \multirow{2}{*}{0,016} & 1 & \multirow{2}{*}{$1,07-1,91$} \\
\hline 5 ou mais & $1065(92,2)$ & $89(7,8)$ & & 1,43 & \\
\hline \multicolumn{6}{|c|}{ Tipo de construção } \\
\hline Tijolo/alvenaria & $2841(93,7)$ & $192(6,3)$ & \multirow{2}{*}{0,271} & 1 & \multirow{2}{*}{$0,66-4,29$} \\
\hline Outros & $44(89,8)$ & $5(10,2)$ & & 1,68 & \\
\hline \multicolumn{6}{|c|}{ Abastecimento de água } \\
\hline Rede pública & $2769(93,6)$ & $189(6,4)$ & \multirow{2}{*}{0,978} & 1 & \multirow{2}{*}{$0,49-2,10$} \\
\hline Outros & $116(93,5)$ & $8(6,5)$ & & 1,01 & \\
\hline \multicolumn{6}{|c|}{ Tratamento de água } \\
\hline Com tratamento & $2273(93,1)$ & $168(6,9)$ & \multirow{2}{*}{0,030} & 1 & \multirow{2}{*}{$0,43-0,96$} \\
\hline Sem tratamento & $611(95,0)$ & $29(4,5)$ & & 0,64 & \\
\hline \multicolumn{6}{|l|}{ Iluminação } \\
\hline Com relógio & $2603(93,6)$ & $179(6,4)$ & \multirow{2}{*}{0,770} & 1 & \multirow{2}{*}{$0,56-1,53$} \\
\hline Outros & $282(94,0)$ & $18(6,0)$ & & 0,93 & \\
\hline \multicolumn{6}{|c|}{ Escoamento sanitário } \\
\hline Rede pública & $2559(93,4)$ & $180(6,6)$ & \multirow{2}{*}{0,249} & 1 & \multirow{2}{*}{$0,45-1,24$} \\
\hline Outros & $326(95,0)$ & $17(5,0)$ & & 0,74 & \\
\hline
\end{tabular}




\begin{tabular}{|c|c|c|c|c|c|}
\hline \multicolumn{6}{|l|}{ Destino do lixo } \\
\hline Coletado & $2793(93,5)$ & $195(6,5)$ & \multirow{2}{*}{0,086} & 1 & \multirow{2}{*}{$0,08-1,27$} \\
\hline Outros & $92(97,9)$ & $2(2,1)$ & & 0,31 & \\
\hline \multicolumn{6}{|l|}{ Tipo de domicílio } \\
\hline Apartamento/casa & $2583(93,4)$ & $184(6,6)$ & \multirow{2}{*}{0,083} & 1 & \multirow{2}{*}{$0,34-1,074$} \\
\hline Outros & $302(95,5)$ & $13(4,1)$ & & 0,60 & \\
\hline \multicolumn{6}{|l|}{ Situação do domicílio } \\
\hline Alugado/financiado & $333(92,0)$ & $29(8,0)$ & 0,068 & 1 & \\
\hline Próprio & $1761(93,2)$ & $128(6,8)$ & 0,399 & 1,20 & $0,79-1,82$ \\
\hline Outro & $789(95,2)$ & $40(4,8)$ & 0,053 & 0,70 & $0,48-1,01$ \\
\hline
\end{tabular}

* Valores incompletos: $66,7 \%$

Com relação às variáveis relacionadas à família, o número de pessoas na casa (cinco ou mais) encontrou-se associado, a maior, à chance $(\mathrm{OR}=1,74)$ de ocorrência de trabalho infantil ( $\mathrm{p}<0,001$ ) (Tabela 3). Não foi observada uma boa concordância entre as variáveis número de cômodos e número de pessoas na casa (Índice de Kappa=0,11).

As famílias com presença de alguma pessoa com deficiência entre seus membros apresentaram maior porcentagem de trabalho infantil. No entanto, essa diferença não foi estatisticamente significativa $(p=0,918)$. Ambas as variáveis não apresentaram nenhum dado incompleto (Tabela 3).

\section{Tabela 3}

Características do núcleo familiar das famílias inscritas no BEM-BH (2003-2006) e a presença de trabalho infantil

\begin{tabular}{lccccc}
\hline \multirow{2}{*}{ Variável } & \multicolumn{2}{c}{ Trabalho infantil } & Valor p & Odds Ratio & IC (95\%) \\
& Não (\%) & Sim (\%) & & \\
\hline $\begin{array}{l}\text { Número de pessoas na } \\
\text { casa }\end{array}$ & & & & & \\
Até 4 & $2290(90,4)$ & $242(9,6)$ & $<0,001$ & 1 & 1,74 \\
5 ou mais & $5679(84,5)$ & $1041(15,5)$ & & & \\
Pessoa com deficiência & & & & 1 & \\
Sim & $974(85,2)$ & $169(14,8)$ & & $0,30-3,01$ \\
Não & $6995(86,3)$ & $1114(13,7)$ & 0,337 & 0,92 & $0,77-1,09$ \\
\hline
\end{tabular}




\begin{tabular}{llllll}
\hline Renda per capita $(\boldsymbol{R} \$)^{*}$ & & & & & \\
$0-25,71$ & $1421(87,1)$ & $210(12,9)$ & 0,060 & 1 & \\
$25,72-45,00$ & $1386(85,6)$ & $233(14,3)$ & 0,234 & 1,13 & $0,92-1,38$ \\
$45,01-82,97$ & $1289(84,6)$ & $252(15,4)$ & 0,042 & 1,23 & $1,01-1,50$ \\
$>82,98$ & $1388(84,0)$ & $265(16,0)$ & 0,010 & 1,29 & $1,06-1,57$ \\
\hline
\end{tabular}

* Valores incompletos: $29 \%$

Quanto à renda per capita não foi observada diferença significativa entre as famílias que apresentam uma renda de 0 a 25,71 reais por pessoa - utilizada como referência na análise estratificada desta variável - e as famílias com renda de 25,72 a 45,00 reais $(p=0,234)$. Entretanto, houve diferença estatisticamente significativa na renda das famílias referência e daquelas com renda de 45,01 a 82,97 reais $(p=0,042)$ e 82,98 ou mais reais $(p=0,010)$. Nesta variável encontrou-se um gradiente dose-resposta: quanto maior a renda familiar per capita maior a prevalência de trabalho infantil nas famílias (ver Tabela 3). Vale ressaltar que 25\% das famílias apresentaram renda per capita acima do critério para a admissão no programa.

Considerando-se as características maternas, não foi observada uma boa concordância entre as variáveis presença de cônjuge na casa e estado civil. Dessa forma, optou-se por privilegiar a análise da variável presença do cônjuge em detrimento da variável estado civil, pois muitas vezes esta condição não coincide com a presença de um companheiro no domicílio. A presença de cônjuge na casa revelou-se como fator de proteção para o trabalho infantil $(\mathrm{p}<0,001)$. Quando a mãe estava inserida no mercado de trabalho identificou-se uma maior e significativa $(\mathrm{p}<0,001)$ chance de TI (14,8\%) em comparação com aquelas famílias em que as mães não estavam trabalhando (12,1\%) (Tabela 4$)$.

Em relação ao grau de instrução da mãe, observou-se associação negativa entre a escolaridade da mãe (anos de estudo) e a chance de ocorrência de trabalho infantil. Em famílias cujas mães estudaram durante 0-3 anos encontrou-se prevalência de $16,6 \%$ de trabalho infantil, com $4-7$ anos de estudo de $11,8 \%$, com 8-10 anos de estudo de $11,4 \%$ e naquelas com as mães tendo estudado mais de 10 anos de 7,4\%. Esta última categoria foi utilizada para comparação e encontrou-se uma diferença estatisticamente significativa entre este grupo e aqueles com menos de 3 anos de estudo $(p=0,004)$. Destaca-se a força da associação desta variável com o registro de trabalho infantil nas famílias (ver Tabela 4).

Quanto ao fato de a família receber outro benefício governamental, famílias cujas mães são beneficiárias de algum outro programa do governo tiveram maior chance de ocorrência de TI (13,9\%) quando comparadas com famílias que não têm 
nenhum outro benefício além do Bolsa-Escola (12,5\%), no entanto esta diferença não foi significativa $(\mathrm{p}=0,47)$ (ver Tabela 4$)$.

\section{Tabela 4}

Características maternas das famílias inscritas no BEM-BH (2003-2006)

e a presença de trabalho infantil

\begin{tabular}{|c|c|c|c|c|c|}
\hline \multirow{2}{*}{ Variável } & \multicolumn{2}{|c|}{ Trabalho infantil } & \multirow{2}{*}{ Valor $p$} & \multirow{2}{*}{$\begin{array}{l}\text { Odds } \\
\text { Ratio }\end{array}$} & \multirow{2}{*}{ IC $(95 \%)$} \\
\hline & Não (\%) & $\operatorname{Sim}(\%)$ & & & \\
\hline \multicolumn{6}{|l|}{ Cônjuge na casa } \\
\hline Sim & $4033(88)$ & $549(12)$ & \multirow{2}{*}{$<0,001$} & 1 & \multirow{2}{*}{$1,22-1,54$} \\
\hline Não & $3936(84,3)$ & $734(15,7)$ & & 1,37 & \\
\hline \multicolumn{6}{|l|}{$\begin{array}{l}\text { Participação em outros } \\
\text { programas }\end{array}$} \\
\hline Sim & $7669(86,1)$ & $1240(13,9)$ & \multirow{2}{*}{0,467} & 1 & \multirow{2}{*}{$0,64-1,23$} \\
\hline Não & $300(87,5)$ & $43(12,5)$ & & 0,89 & \\
\hline \multicolumn{6}{|l|}{$\begin{array}{l}\text { Situação no mercado de } \\
\text { trabalho* }\end{array}$} \\
\hline Sem inserção trabalhista & $2934(87,9)$ & $402(12,1)$ & \multirow{2}{*}{$<0,001$} & 1 & \multirow{2}{*}{$1,11-1,44$} \\
\hline Com inserção trabalhista & $4812(85,2)$ & $834(14,8)$ & & 1,26 & \\
\hline \multicolumn{6}{|l|}{ Grau de instrução da mãe $e^{* *}$} \\
\hline$>10$ anos & $137(92,6)$ & $11(7,4)$ & $<0,001$ & 1 & \\
\hline 8-10 anos & $460(88,6)$ & $59(11,4)$ & 0,171 & 1,60 & $0,82-3,13$ \\
\hline 4-7 anos & $3872(88,4)$ & $517(11,8)$ & 0,108 & 1,66 & $0,90-3,10$ \\
\hline 0-3 anos & $3391(83,4)$ & $674(16,6)$ & 0,004 & 2,48 & $1,33-4,60$ \\
\hline
\end{tabular}

* Valores incompletos: 2,9\% / ** Valores incompletos: 1,4\%

$\mathrm{Na}$ análise multivariada foram incluídas no modelo inicial 8.948 (96,7\% do total de famílias incluídas no estudo) com prevalência de trabalho infantil de 15,9\%. Em virtude da boa adequação do modelo, avaliada por meio do teste de Hosmer e Lemeshow, o modelo inicial foi considerado o modelo final (Tabela 5), incluindo as variáveis número de pessoas na casa, presença do cônjuge na casa, grau de instrução materna e situação materna no mercado de trabalho. Os resultados observados coincidem com a análise univariada.

O poder do teste calculado a posteriori, a partir da metodologia de Hosmer e Lemeshow utilizando a variável presença do cônjuge na casa, foi de 99,9\%. O tamanho da amostra necessária para se obter um poder de $80 \%$ seria de 1.120 famílias. 
O cálculo do modelo probabilístico mostrou que a probabilidade de ocorrência do trabalho infantil é de $24 \%$ em uma família com cinco ou mais pessoas no domicílio, cujo núcleo familiar é monoparental e a genitora declara inserção trabalhista e baixa escolaridade (0-3 anos de estudo). No contraponto, estão as famílias com até quatro pessoas no domicílio, com presença do cônjuge, cuja mãe não apresenta inserção trabalhista e relata escolaridade elevada (mais de 10 anos de estudo). A probabilidade de trabalho infantil nas famílias com essas características diminui para $3 \%$.

\section{Tabela 5}

Análise multivariada das variáveis associadas ao trabalho infantil nas famílias inscritas no BEM-BH (2003-2006)*

\begin{tabular}{|c|c|c|c|c|c|}
\hline Variável & Estimativa & Erro-padrão & Valor $\mathbf{p}$ & $X^{2}$ & OR (IC 95\%) \\
\hline $\begin{array}{l}\text { Quantidade de } \\
\text { pessoas na casa } \\
\text { (5 ou mais membros) }\end{array}$ & 0,671 & 0,080 & $<0,001$ & 70,955 & $1,96(1,67-2,29)$ \\
\hline $\begin{array}{l}\text { Situação no mercado } \\
\text { de trabalho (mãe com } \\
\text { inserção trabalhista) }\end{array}$ & 0,201 & 0,068 & 0,003 & 8,714 & $1,22(1,07-1,40)$ \\
\hline $\begin{array}{l}\text { Ausência do cônjuge } \\
\text { na casa }\end{array}$ & 0,449 & 0,066 & $<0,001$ & 46,04 & $1,57(1,38-1,78)$ \\
\hline $\begin{array}{l}\text { Grau de instrução da } \\
\text { mãe (referência }>10 \\
\text { anos) }\end{array}$ & & & $<0,001$ & 48,813 & \\
\hline 8-10 anos & 0,515 & 0,359 & 0,151 & 2,059 & $1,67(0,83-3,38)$ \\
\hline 3-7 anos & 0,587 & 0,332 & 0,077 & 3,120 & $1,80(0,94-3,45)$ \\
\hline$<3$ anos & 0,990 & 0,332 & 0,003 & 8,896 & $2,69(1,40-5,16)$ \\
\hline
\end{tabular}

* N=8.949 famílias.

\section{Discussão}

A prevalência de TI encontrada no grupo estudado está, provavelmente, subestimada em razão de, pelo menos, dois fatores: 1 ) a qualidade da fonte dos dados sobre a ocorrência de TI em cada família; 2) os constrangimentos das famílias na declaração do evento haja vista os objetivos do BEM-BH em erradicar o TI. Apesar de subestimada, a prevalência de trabalho infantil encontrada $(13,9 \%)$ é maior do que 
aquela descrita em uma cidade no sul do país, de 10\% (Facchini et al., 2003), e maior do que a referida na população brasileira, de 11,5\% (Ipea, 2007). A baixa renda, condição para a participação no BEM-BH, explicaria a diferença em relação à realidade brasileira em geral. Contribui para essa explicação o achado sobre a participação das famílias estudadas em outros programas de transferência de renda.

Contudo, avaliações precedentes do BEM-BH indicam o cumprimento da meta de garantir e aumentar a frequência escolar da população-alvo (PBH/UFMG, 2004), à semelhança de outros casos brasileiros (Ferro \& Kassouf, 2005; Carvalho, 2004; Nobre, 2003). Em uma capital localizada na Região Nordeste, foram observados crianças e adolescentes trabalhadores frequentes às aulas (Oliveira \& Francischini, 2003). Na Região Sudeste, mais de 75\% dos estudantes de 11 a 19 anos matriculados em escolas públicas de duas cidades estavam inseridos no mercado de trabalho (Fischer et al., 2003).

As crianças e os adolescentes matriculados nas escolas e que mantêm suas atividades laborais encontram-se atrasados em relação à série que deveriam estar cursando (Ávila, 2007; Facchini et al., 2003; Marques, 2003; OIT, 2002; Oliveira \& Robazzi, 2001; Schwartzman, 2001). Adicionalmente, não é incomum o abandono precoce da escola (Santana et al., 2005; Oliveira \& Robazzi, 2001). A evasão escolar pode ser atribuída ao cansaço e à falta de tempo, ambos associados à dupla jornada [trabalho-escola] (OIT, 2003).

Contrariando outros estudos (Cardoso \& Souza, 2003; OIT, 2002; Ferreira, 2001; Oliveira \& Robazzi, 2001; Aderinto, 2000; Conley, 2000), quanto maior a renda familiar maior a probabilidade de trabalho infantil na população estudada. A interpretação desse dado merece cautela, pois o aumento da renda pode ser um resultado da prática de TI. É plausível supor que o trabalho infantil estaria de fato contribuindo para o aumento da renda familiar. Em situação de miséria, o trabalho de crianças e adolescentes garantiria pequenos rendimentos, os quais seriam considerados significativos para aquela família (Facchini et al., 2003).

Os resultados obtidos e a literatura consultada permitem afirmar sobre a influência dos atributos familiares na prevalência de TI. A decisão quanto à inserção de crianças e adolescentes no mercado de trabalho está na esfera familiar. O tamanho e a estrutura familiar são características demográficas relevantes, pois famílias extensas têm maior probabilidade de TI (Cardoso \& Souza, 2003). Na Nigéria, as crianças em situação de trabalho de rua eram provenientes de famílias com cinco ou mais filhos (Aderinto, 2000).

Famílias chefiadas por mulheres têm muito mais chances de enviarem seus filhos para o trabalho. A ausência do pai foi associada ao trabalho infantil no estudo de Marques (2001). Para o autor, muitas crianças se veem obrigadas a ajudar 
financeiramente a mãe quando não existe a figura paterna. Na mesma população deste estudo, Cruz e Assunção (2008) evidenciaram os vários sentidos que os sujeitos buscam para a prática do trabalho infantil. Os resultados das autoras mostraram que, principalmente, no caso de famílias monoparentais, a prática do TI está associada à geração. Sabe-se que os pais de menores que trabalham geralmente trabalham desde cedo e raramente frequentam a escola (Cruz \& Assunção, 2008; Marques, 2001; Cardoso \& Souza, 2003; Oliveira \& Robazzi, 2001).

Viu-se neste estudo associação negativa entre a escolaridade da mãe e a ocorrência de trabalho infantil, ou seja, as famílias cujos genitores apresentam baixa escolaridade têm maior porcentual de trabalho infantil, à semelhança dos achados de outros autores (Cardoso \& Souza, 2003; Ferreira, 2001). A esse propósito, Santana et al. (2005) evidenciaram menor escolaridade das mães dos adolescentes do sexo masculino trabalhadores na Bahia, Brasil, em comparação à das mães dos não trabalhadores. Na Nigéria, Aderinto (2000) encontrou uma diferença significativa entre o nível educacional dos pais de crianças inseridas no trabalho em situação de rua quando comparado ao dos pais do grupo frequente às aulas.

A escolaridade é uma variável estável. Por essa razão porta melhor capacidade explicativa de situações sociais históricas, não sendo influenciada por mudanças conjunturais. Nessa direção, autores contemporâneos sinalizam o seu caráter marcador de outras condições sociais, entre elas menciona-se a taxa de mortalidade infantil (Friche et al., 2006; Vlahov, 2005).

Viu-se uma maior chance de trabalho infantil quando a mãe está inserida no mercado de trabalho. É razoável supor que, ao saírem de casa para trabalhar, as mães levem consigo suas crianças, principalmente nos casos de trabalho informal. Cruz e Assunção (2008) evidenciaram estruturas de trabalho do tipo familiar organizadas em situação de rua, nas quais todos os membros participam sob a coordenação dos genitores. Os resultados apresentados, entretanto, estão em desacordo com os achados de Grootaert e Patrinus (1999), que associam o desemprego dos pais ao trabalho infantil relacionando-o com a escassez de recursos materiais.

\section{Conclusão}

Finalmente, a probabilidade de trabalho infantil está fortemente (24\%) relacionada às características familiares mencionadas (número de membros, presença do cônjuge e escolaridade e inserção trabalhista da mãe) e convoca futuras reflexões sobre a prática e o alcance das políticas de transferência de renda.

O presente estudo apresenta algumas limitações que merecem ser destacadas. O delineamento transversal apresenta limitações no que se refere às inferências 
causais, já que as informações sobre exposição e desfecho são coletadas num mesmo momento. Ressente-se da escassez de investigações sobre a prática de TI em populações inseridas em programas de transferência de renda, as quais poderiam enriquecer as interpretações apresentadas. Ressalta-se o possível viés de informação, como já mencionado, pois as tentativas de erradicação do TI teriam influência sobre a declaração do fenômeno estudado. Dessa forma, o número real de famílias com trabalho infantil pode ter sido subestimado.

\section{Referências}

ADERINTO, A.A. Social correlates and coping measures of street-children: a comparative study of street and non-street children in south-western Nigeria. Child Abuse \& Neglect, Emsford, v. 24, n. 9, p. 1199-1213, 2000.

AGUIAR, M.; ARAÚJO, C.H. Bolsa-Escola: educação para enfrentar a pobreza. 2. ed. Brasília, DF: Unesco, 2002.

ÁVILA, A.S. Trabajo infantil e inasistencia escolar. Revista Brasileira de Educação, Rio de Janeiro, v. 12, n. 34, p. 68-81, 2007.

BELO HORIZONTE. Prefeitura Municipal; Universidade Federal de Belo Horizonte. Perfil sociodemográfico das crianças e adolescentes trabalhadores do Programa Bolsa-Escola da PBH-MG - 1997-2004. Belo Horizonte: UFMG, 2004. (Relatório).

BRASIL. Lei n. 8.069, de 13 de julho de 1990. Dispõe sobre o Estatuto da Criança e do Adolescente e dá outras providências. Diário Oficial da União, Brasília, DF, 16 julho 1990.

BRASIL. Ministério do Trabalho e Emprego. Trabalho precoce: saúde em risco. Brasília, DF, 2000.

CAMPOS, H.R.; ALVERGA, A.R. Trabalho infantil e ideologia: contribuição ao estudo da crença indiscriminada na dignidade do trabalho. Estudos de Psicologia, Natal, v. 6, n. 2, p. 227-233, 2001.

CARDOSO, E.; SOUZA, A.P. The impact of cash transfers on child labor and school attendance in Brazil. Trabalho apresentado em Lacea - Latin American and Caribbean Economics Association, Las Pueblas, 2003.

CARVALHO, I.M.M. Algumas lições do programa de erradicação do trabalho infantil. São Paulo em Perspectiva, São Paulo, v. 18, n. 4, p. 50-61, 2004.

COMISSÃO ECONOMICA PARA AMÉRICA LATINA E CARIBE (Cepal). Panorama social da América Latina. Santiago del Chile, 2006. 
CONLEY, J. Child labor: robbing children of their youth. Pediatric Nursing, Pitman, v. 26, n. 6, 2000.

CRUZ, M.N.A. Estrutura, organização e prática do trabalho infantil em situação de rua. 2005. Dissertação (Mestrado) - Faculdade de Medicina, Universidade Federal de Minas Gerais, Belo Horizonte.

CRUZ, M.N.A.; ASSUNÇÃO, A.A. Estrutura e organização do trabalho infantil em situação de rua em Belo Horizonte, MG, Brasil. Saúde e Sociedade, São Paulo, v. 17, p. 132-143, 2008.

FACCHINI, L.A. et al. Trabalho infantil em Pelotas: perfil ocupacional e contribuição à economia. Ciência E Saúde Coletiva, Rio de Janeiro, v. 8, n. 4, p. 953-961, 2003.

FERREIRA, M.A.F. Trabalho infantil e a produção acadêmica nos anos 90: tópicos para reflexão. Estudos de Psicologia, Natal, v. 6, n. 2, p. 213-225, 2001.

FERRO, A.R.; KASSOUF, A.L. Avaliação do impacto dos Programas Bolsa-Escola sobre o trabalho infantil no Brasil. Pesquisa e Planejamento Econômico, Rio de Janeiro, v. 35, n. 3, 2005.

FISCHER, F.M. et al. Occupational accidents among middle and high school students of the state of São Paulo, Brazil. Revista de Saúde Pública, São Paulo, v. 37, n. 3, p. 351-356, 2003.

FORASTIERI, V. Children at work: health and safety risks. Geneva: International Labour Office, 1997.

FRANKLIN, R.N. et al. Trabalho precoce e riscos à saúde. Adolescência Latinoamericana, Porto Alegre, v. 2, n. 2, p. 80-89, 2001.

FRICHE, A.A.L. et al. Indicadores de saúde materno-infantil em Belo Horizonte, Minas Gerais, Brasil, 2001: análise dos diferenciais intraurbanos. Caderno de Saúde Pública, Rio de Janeiro, v. 22, n. 9, p. 1955-1965, 2006.

GROOTAERT, C.; PATRINUS, H. The policy analisys of child labor: a comparative study. Nova York: St. Martin's, 1999.

INSTITUTO BRASILEIRO DE GEOGRAFIA E ESTATÍSTICA (IBGE). Síntese de indicadores sociais: uma análise das condições de vida da população brasileira. Rio de Janeiro: IBGE, 2007.

INSTITUTO DE PESQUISA ECONÔMICA APLICADA (Ipea). PNAD 2006 primeiras análises: demografia, educação, trabalho, previdência, desigualdade de renda e pobreza. Brasília, DF ; Rio de Janeiro: Ipea, 2007. 
LAGARDE, M.; HAINES, A.; PALMER, N. Conditional cash transfers for improving uptake of health interventions in low- and mild-income countries. Journal of the American Medical Association, Chicago, v. 298, n. 16, p. 1900-1910, 2007.

MARQUES, M.E.; NEVES, M.A.; CARVALHO NETO, A. (Org.). Trabalho infantil: a infância roubada. Belo Horizonte: PUC Minas; Instituto de Relações do Trabalho, 2002.

MARQUES, V.R.B. Histórias de higienização pelo trabalho: crianças paranaenses no novecentos. Cadernos Cedes, Campinas, v. 23, n. 59, p. 57-78, 2003.

MARQUES, W.E.U. Infâncias (pre)ocupadas: trabalho infantil, família e identidade. Brasília, DF: Plano, 2001.

MINISTÉRIO DO TRABALHO E EMPREGO (MTE). Mapa de indicativos do trabalho da criança e do adolescente. Brasília, DF: Ministério do Trabalho e Emprego, 2005.

NOBRE, L.C.C. Trabalho de crianças e adolescentes: os desafios da intersetorialidade e o papel do Sistema Único de Saúde. Ciência \& Saúde Coletiva, Rio de Janeiro, v. 8, n. 4, p. 963-971, 2003.

OLIVEIRA, B.R.G.; ROBAZZI, M.L.C.C. O trabalho na vida dos adolescentes: alguns fatores determinantes para o trabalho precoce. Revista Latino-Americana de Enfermagem, Ribeirão Preto, v. 9, n. 3, p. 83-89, 2001.

OLIVEIRA, I.C.C.; FRANCISCHINI, R. A importância da brincadeira: o discurso de crianças trabalhadoras e não trabalhadoras. Psicologia: teoria e prática, São Paulo, v. 5, n. 1, p. 41-56, 2003.

ORGANIZAÇÃO INTERNACIONAL DO TRABALHO (OIT). Combate ao trabalho infanto-juvenil no Brasil: avanços e desafios. Brasília, DF: OIT, 2002.

ORGANIZAÇÃO INTERNACIONAL DO TRABALHO (OIT). Boas práticas de combate ao trabalho infantil: os 10 anos do Ipec no Brasil. Brasília, DF: OIT, 2003.

ORGANIZAÇÃO INTERNACIONAL DO TRABALHO (OIT). O fim do trabalho infantil: um desafio ao nosso alcance. Brasília, DF: OIT, 2006.

PAGANO, M.; GAUVREAU, K. Princípios de bioestatística. São Paulo: Thomson Learning, 2006.

PEARCE, N. Effect measures in prevalence studies. Environmental Health Perspectives, Wellington, v. 112, p. 1046-1050, 2004.

PERO, V.; SZERMAN, D. The new generation of social programs in Brazil. In: UFRJ/ IE SEMINÁRIOS DE PESQUISA, 2005, Rio de Janeiro. Disponível em: http://www. 
ie.ufrj.br/publicacoes/serie_seminarios_de_pesquisa/the_new_generation_of_social_programs_in_brazil.pdf > Acesso em: 1 nov. 2007.

SANTANA, V.S. et al. Adolescent students who work: gender differences in school performances and self-perceived health. International Journal of Occupational and Environmental Health, [S.1.], v. 11, n. 3, p. 294-301, 2005.

SCHIAFFINO, A. et al. Odds ratio o razón de proporciones? Su utilización en estudios transversales. Gaceta Sanitaria, Barcelona, v. 17, n. 1, p. 70-74, 2002.

SCHWARTZMAN, S. Trabalho infantil no Brasil. Brasília, DF: OIT, 2001.

VLAHOV, D. et al. Perspectives on urban conditions and population health. Cadernos de Saúde Pública, Rio de Janeiro, v. 21, n. 3, p. 949-957, 2005.

Recebido em 12 de setembro de 2009.

Aprovado em 2 de outubro de 2010. 